\title{
Analisis Risiko Potensi Bahaya dan Pengendaliannya Dengan Metode HIRADC pada PT. IGASAR Kota Padang Sumatera Barat
}

\author{
Taufiq Ihsan $^{1 *}$, Aulia Safitri ${ }^{2}$, Dhywa Putra Dharossa ${ }^{3}$ \\ ${ }^{1,2,3}$ Jurusan Teknik Lingkungan Fakultas Teknik Universitas Andalas, Kampus Unand Limau Manis \\ Kota Padang, Indonesia 25163 \\ *Koresponden email: taufiqihsan@eng.unand.ac.id
}

Diterima: 8 Maret 2020

Disetujui: 27 Maret 2020

\begin{abstract}
PT IGASAR was one of the companies affiliated with PT Semen Padang with business activities in the fields of engineering, cement distribution, transportation, heavy equipment rental, cement-based building materials industry, manufacturing, general contractor, and developer. Some work accidents were still found in activities at this company. It was essential to making hazard identification, risk assessment, and determined the type of control in some areas. There are work accidents in PT IGASAR in as many as five cases in 2017 - 2018. One way was to use the Hazard Identification Risk Assessment Determine Control (HIRADC) Method. A risk analysis was done by looking at the opportunities and the severity of the hazards. Based on the results of the risk analysis, it was found that activities that were low risk, very high risk was absent while the medium risk was $100 \%$. The risk control measures include the provision of personal protective equipment, the rule of safety signs, equipment maintenance, and the creation of road area boundaries.
\end{abstract}

Keywords: PT IGASAR, accidents, hazard, risk, control

\begin{abstract}
Abstrak
PT. IGASAR yang mempunyai kegiatan usaha di bidang engineering, distribusi semen, transportasi, rental alat berat, industri bahan bangunan berbasis semen, manufacturing, general contractor, dan pengembangan, adalah salah satu perusahaan yang berafiliasi dengan PT. Semen Padang. Beberapa kasus kejadian kecelakaan kerja masih dijumpai pada kegiatan di perusahaan ini. Oleh sebab itu, penting dilakukan identifikasi bahaya, penilaian risiko dan menentukan jenis pengendalian pada bagian yang ditemukan terjadinya kecelakaan kerja di PT IGASAR sebanyak lima kasus pada Tahun 2017-2018. Salah satu cara adalah memakai Metode Hazard Identification Risk Assessment Determine Control (HIRADC). Analisis risiko dilakukan dengan melihat peluang dan tingkat keparahan terjadinya bahaya. Berdasarkan hasil analisis risiko yang dilakukan, pada PT IGASAR termasuk pada berisiko sedang yakni sebesar $100 \%$. Saran terkait pengendalian risiko antara lain adalah memberi alat pelindung diri, mengadakan dan menempatkan safety sign, melakukan maintenance peralatan dan membuat batas area jalan.
\end{abstract}

Kata Kunci: PT IGASAR, kecelakaan, bahaya, risiko, pengendalian

\section{Pendahuluan}

Sejalan dalam pelaksanaan kegiatan globalisasi di segala bidang, perindustrian di Indonesia pun menunjukkan perubahan. Perubahan itu ditunjukkan melalui semakin pesatnya teknologi yang dipakai dalam menjalankan proses produksi, sehingga dapat meningkatkan efisiensi dan produktivitas kerja. Namun, perubahan ini dapat pula memunculkan risiko terjadinya kecelakaan kerja yang disebabkan oleh kelalaian dan kesalahan manusia. Dalam meningkatkan efisiensi dan efektivitas perlindungan keselamatan dan kesehatan kerja (K3), diperlukan upaya pelaksanaan K3 yang terencana, terstruktur, terintegrasi dan terukur melalui Sistem Manajemen Keselamatan dan Kesehatan Kerja (SMK3) [1].

Tempat kerja merupakan lokasi yang memiliki tingkat bahaya yang sangat tinggi bagi keselamatan manusia baik itu disebabkan oleh kondisi lingkungan tersebut maupun human error. Termaktub pada pasal 87 dalam Undang-Undang No. 13 Tahun 2003 menyatakan bahwa "setiap perusahaan yang mempekerjakan lebih dari 100 karyawan atau yang sifat proses dan bahan produksinya mengandung bahaya karena dapat menyebabkan kecelakaan kerja berupa ledakan, kebakaran, pencemaran dan penyakit akibat kerja diwajibkan menerapkan dan melaksanakan SMK3" [2]. 
Secara harfiah risiko kecelakaan dapat didefinisikan sebagai perpaduan dari kemungkinan suatu kejadian dan konsekuensinya akibat kejadian tersebut. Berdasarkan pengertian tersebut, analisis risiko kecelakaan kerja dapat didefinisikan sebagai suatu kegiatan menyelidiki atau mencari kebenaran terkait probabilitas suatu kejadian beserta konsekuensinya [3,4]. Kecelakaan kerja bukan hanya dari segi kelalaian pekerja. Seperti halnya ref. [5] melaporkan bahwa kondisi fisik lingkungan kerja dapat berimplikasi pada kejadian kecelakaan kerja.

Guna meminimalisir risiko kecelakaan kerja dalam industri, maka diperlukan upaya yang terkoordinasi dalam pengelolaan risiko bahaya yang mungkin terjadi dan dialami oleh pekerja. Pengelolaan risiko saat bekerja dapat dilakukan dengan melakukan identifikasi bahaya hingga melakukan penilaian terhadap risiko itu sendiri. Melalui penilaian risiko, maka kecelakaan kerja yang berpotensi mengakibatkan cedera hingga berdampak pada kerugian perusahaan, dapat dikurangi bahkan dihilangkan [1].

Dalam penerapan SMK3, acuan yang sudah sering dan banyak diterapkan di kalangan industri dunia adalah standar sistem OHSAS 18001. Sesuai permintaan dan tuntutan dari OHSAS 18001, terdapat klausul 4.3.1 menyebutkan bahwa organisasi harus menetapkan prosedur dan melakukan Identifikasi Bahaya (Hazards Identification), Penilaian Risiko (Risk Assessment), dan Pengendalian Risiko (Determining Control) atau disingkat HIRADC/Hazard Identification Risk Assessment Determine Control [6].

PT IGASAR memiliki karyawan yang berjumlah 282 orang, terdiri dari: karyawan tetap 120 orang, out sourcing 127 orang dan karyawan kontrak sebanyak 35 orang dengan komposisi staf $16 \%$ dan non staf $84 \%$. PT. IGASAR banyak menggunakan peralatan-peralatan berat seperti excavator, bulldozer, dump truck, loader, crane dan forklift dimana dalam pengoperasian peralatan tersebut maka berpotensi menyebabkan tingginya risiko kecelakaan kerja yang timbul. Selain itu, bagi perusahaan dengan jumlah pekerja lebih dari 100 orang, sudah wajib melaksanakan pelaksanaan SMK3. Adapun rekapitulasi total kecelakaan kerja yang terjadi di PT. IGASAR selama dua tahun (2017-2018) dapat dilihat pada Tabel 1. Meskipun hanya ada lima kasus kecelakaan, namun PT IGASAR yang memiliki kebijakan nol kasus kecelakaan, maka berdasarkan hal itu dilakukan analisis risiko kecelakaan kerja terhadap kegiatan yang berhubungan dengan peralatan yang digunakan oleh para karyawan PT. IGASAR.

Tabel 1. Data kecelakaan kerja PT IGASAR 2017-2018

\begin{tabular}{ccc}
\hline Jenis Kecelakan & Cedera & Penyebab Kecelakaan \\
\hline Kecelakaan di jalan & Patah tangan & Perbuatan dan keadaan yang tidak aman \\
Kecelakaan proses industri & Luka pada kepala & Perbuatan dan keadaan yang tidak aman \\
Kecelakaan proses industri & Bahu sebelah kiri & Perbuatan dan keadaan yang tidak aman \\
Kecelakaan proses industri & Tangan terluka & Perbuatan dan keadaan yang tidak aman \\
Kecelakaan proses industri & Muka dan mata kena air aki & Pemasangan pengaman accu mobil \\
\hline & Sumber: Data kecelakaan kerja PT IGASAR
\end{tabular}

\section{Metodologi Penelitian}

Penelitian ini melakukan pengidentifikasian bahaya kecelakaan kerja berdasarkan data kecelakaan kerja pada Tahun 2017-2018 di PT. IGASAR, melakukan penilaian risiko berdasarkan data kecelakaan kerja dengan melihat tingkat kemungkinan, keparahan serta dampak pada kecelakaan kerja yang terjadi.

Selanjutnya melakukan pengidentifikasian sumber bahaya pada area kerja PT. IGASAR mencakup semua kegiatan yang ada serta pada wilayah produksi. Sumber bahaya yang telah didapatkan pada tahap identifikasi bahaya berikutnya dilakukan penilaian risiko dengan metode HIRADC guna mengetahui tingkatan risiko terhadap bahaya itu sendiri.

Dalam penerapan SMK3 yang baik bagi perusahaan, maka HIRADC merupakan salah satu pilihan yang sering dipakai. HIRADC mencakupi juga identifikasi kecelakaan kerja dengan penilaian risiko. Hasil akhir dari suatu kegiatan analisis risiko kerja adalah menentukan status dari risiko (risk event status) yang diperoleh dari hasil perkalian antara probabilitas dengan dampak dari suatu risiko kecelakaan kerja [7]. Perhitungan analisis risiko membutuhkan skoring berdasarkan kriteria yang dapat dilihat pada Tabel 2, dan 3 [8]. Analisis risiko menghasilkan data dan informasi berupa tingkatan risiko (Risk Rate/ RR) yang selanjutnya digunakan guna mengevaluasi risiko serta merumuskan tindakan penanganan terhadap risiko yang mungkin terjadi. Perhitungan RR dapat dihitung dengan persamaan berikut [8]. 
$\mathrm{RR}=\mathrm{L} \times \mathrm{C}$

dimana:

RR : Risk Rate (Tingkat risiko)

$\mathrm{C} \quad$ : Consequence (Akibat)

L : Likelihood (Kemungkinan)

Tabel 2. Tingkat kemungkinan (Likelihood)

\begin{tabular}{cll}
\hline Tingkatan & Keterangan & Uraian \\
\hline 1 & Very Unlikely & Memungkinkan tidak pernah terjadi \\
2 & Unlikely & Dapat terjadi, tapi jarang \\
3 & Possible & Dapat terjadi pada kondisi tertentu \\
4 & Likely & Dapat terjadi secara berkala \\
5 & Almost certain & Dapat terjadi kapan saja \\
\hline
\end{tabular}

Sumber: AS/NZS 4360, 2004

Tabel 3. Tingkat keparahan dan dampak (Consequence)

\begin{tabular}{cll}
\hline Tingkatan & Keterangan & Uraian \\
\hline 1 & Very Unlikely & Tidak cedera, kerugian finansial rendah. \\
2 & Unlikely & Cedera ringan, kerugian finansial sedang. \\
3 & Possible & $\begin{array}{l}\text { Cedera sedang, butuh penanganan medis, kerugian tinggi. } \\
\text { Cedera berat lebih dari satu orang, kerugian tinggi dan }\end{array}$ \\
& Likely & $\begin{array}{l}\text { gangguan produksi. } \\
\text { Fatal lebih dari satu orang, kerugian sangat tinggi dan } \\
\text { dampak luas yang berdampak panjang dan terhentinya } \\
\text { seluruh kegiatan. }\end{array}$ \\
\hline & Almost certain & Sumber: AS/NZS 4360, 2004
\end{tabular}

Mengacu pada hasil perhitungan analisis risiko (RR) yang diperoleh, maka disusunlah prioritas pengendalian yang sesuai dan tepat. Dalam evaluasi risiko, nilai RR dibandingkan dengan Matriks Risiko yang terlihat pada Tabel 4 [9], sehingga diketahui batasan risiko yang diperbolehkan maupun yang tidak diperbolehkan. Pengendalian dikerjakan terhadap seluruh risiko dalam proses identifikasi bahaya dan dengan mempertimbangkan peringkat risiko guna menentukan prioritas dan tindakan perbaikan serta pengendaliannya. Dalam melaksanakan tindakan pengendalian wajib menganut hierarki pengendalian, diawali dengan dari eliminasi (membuang dan menyisihkan bahan/bagian dari suatu proses berbahaya yang ada pada industri tersebut), substitusi (menukar bahan/peralatan untuk pengendalian proses berbahaya yang ada dalam industri), rekayasa/ engineered (pembuatan, perbaikan dan/atau pemasangan alat guna mengendalikan proses yang berbahaya untuk keselamatan kerja pekerja), administrasi (cara yang terkait dengan penyelenggaraan kebijakan dan pembinaan dalam pengelolaan perusahaan, yang digunakan untuk pengendalian risiko berbahaya) serta persiapan alat pelindung diri yang disesuaikan dengan status dan keadaan perusahaan, ketersediaan dana, biaya personil, faktor lingkungan dan manusia.

Tabel 4. Matriks risiko

\begin{tabular}{llllll}
\hline \multirow{2}{*}{ Likelihood } & \multicolumn{5}{c}{ Consequences } \\
\cline { 2 - 6 } & \multicolumn{2}{c}{1} & 2 & \multicolumn{4}{c}{3} & \multicolumn{1}{c}{5} \\
\cline { 2 - 5 } & (Insignificant) & (Minor) & (Moderate) & (Major) & (Catastrophic) \\
\hline 1 (Very Unlikely) & Low & Low & Low & Medium & Medium \\
2 (Unlikely) & Low & Medium & Medium & Medium & High \\
3 (Possible) & Low & Medium & Medium & High & High \\
4 (Likely) & Medium & Medium & High & High & Very High \\
5 (Almost certain) & Medium & High & High & Very High & Very High \\
\hline
\end{tabular}

Keterangan: Low = 1-3, Medium = 4-9, High =10-16, Very High = 20-25

Sumber: AS/NZS 4360, 2004

\section{Hasil dan Pembahasan}

Pada hasil perhitungan RR, terlihat di Tabel 5, memperlihatkan bahwa kegiatan dengan risiko bahaya rendah (low risk); risiko bahaya tinggi (high risk); serta risiko bahaya sangat tinggi; (very high 
risk) tidak ada. Sedangkan berisiko bahaya sedang (medium risk) sebesar 100\%. Kegiatan yang mempunyai risiko medium dan high wajib untuk lekas dikerjakan pengendalian risikonya sehingga dapat meminimalisir kecelakaan kerja yang akan terjadi.

Berdasarkan risk assessment terdapat 5 potensi bahaya dengan tingkatan medium risk yaitu jatuh dari kendaraan pada saat berangkat bekerja, tertimpa alat pada area produksi batching plan, terpeleset pada area produksi beton cetak, terjepit saat pengecekan kendaraan dan terluka akibat adanya aki yang meledak pada saat memasang pengamanan aki mobil PT. IGASAR. Pengendalian risiko dapat dilakukan dengan memberi alat pelindung diri; mengadakan dan menempatkan safety sign; melakukan maintenance peralatan; dan membuat batas area jalan.

Dengan melihat tetap munculnya kecelakaan kerja yang dialami oleh karyawan PT. IGASAR pada tahun 2017, (dengan menimbang kebijakan perusahan demi mencapai zero accidents) dan untuk meminimalisir terjadinya kecelakaan kerja maka PT. IGASAR telah melakukan beberapa tindakan diantaranya [10 - 16]:

\section{Pembekalan Pelatihan dan Alat Pelindung Diri}

PT. IGASAR membekali pengetahuan dalam bentuk pelatihan mengenai keselamatan kerja biasanya pelatihan ini dilakukan dua kali dalam setahun. Pelatihan ini bersifat internal dan biasanya diikuti oleh semua pekerja di area produksi. Lama pelatihan yang dilakukan beragam mulai dari 8 jam hingga 20 jam, tergantung pada materi dan workshop yang dilakukan. Pelatihan ini bermaksud guna meningkatkan kesadaran, keterampilan dan ilmu pengetahuan bagi pekerja terhadap perlunya menjaga keselamatan dan kesehatan di lokasi kerja.

Untuk meminimalisir kecelakaan kerja pada PT. IGASAR maka tim ahli K3 melengkapi persediaan alat pelindung diri yang sesuai dengan Standar Nasional Indonesia yang disediakan oleh PT IGASAR, diantaranya sarung tangan tahan panas, guna mencegah terkena panas dan api; sepatu safety, yaitu sepatu yang digunakan untuk melindungi kaki dari benda-benda tajam dan benda yang akan membuat kaki luka; pelindung wajah, berfungsi untuk melindungi hidung dari zat-zat berbau menyengat dan debu; serta helm pengelasan yang menjadi pelindung muka dan dapat melindungi area penglihatan. Helm las juga menggunakan lensa absorpsi khusus yang bisa menyaring cahaya yang terlampau terang maupun dari radiasi yang dihasilkan selama proses pengelasan.

Tabel 5. Identifikasi risiko kecelakaan kerja berdasarkan Metode HIRADC dan upaya perbaikan

\begin{tabular}{|c|c|c|c|c|c|c|c|c|}
\hline \multirow[b]{2}{*}{ Aktivitas } & \multirow[b]{2}{*}{ Bahaya } & \multirow[b]{2}{*}{ Konsekuensi } & \multirow{2}{*}{$\begin{array}{c}\text { Tindakan } \\
\text { Pengendalian } \\
\text { (Eksisting) }\end{array}$} & \multicolumn{3}{|c|}{ Risk Rate } & \multirow{2}{*}{$\begin{array}{c}\text { Tambahan } \\
\text { Tindakan } \\
\text { Pengendalian }\end{array}$} & \multirow[b]{2}{*}{$\begin{array}{c}\text { Penanggung } \\
\text { Jawab }\end{array}$} \\
\hline & & & & $\begin{array}{c}\mathrm{L} \\
\text { (Likelihood) }\end{array}$ & $\mathrm{C}$ (Consequence) & $\begin{array}{c}\mathrm{R} \\
\text { (Risk) }\end{array}$ & & \\
\hline $\begin{array}{l}\text { Berangkat } \\
\text { kerja }\end{array}$ & $\begin{array}{l}\text { Jatuh dari } \\
\text { kendaraan }\end{array}$ & Tangan patah & Belum ada & 2 & 3 & Medium & Tidak ada & Ahli K3 \\
\hline $\begin{array}{l}\text { Produksi } \\
\text { Batching Plan }\end{array}$ & Tertimpa & $\begin{array}{ll}\text { Luka } & \text { pada } \\
\text { kepala } & \end{array}$ & $\begin{array}{l}\text { Penggunaan } \\
\text { APD }\end{array}$ & 2 & 2 & Medium & $\begin{array}{l}\text { Peringatan } \\
\text { pemakaian } \\
\text { APD lengkap } \\
\text { saat bertugas }\end{array}$ & Ahli K3 \\
\hline $\begin{array}{l}\text { Pengecekan } \\
\text { kendaraan }\end{array}$ & Terjepit & Tangan luka & $\begin{array}{l}\text { Penggunaan } \\
\text { APD }\end{array}$ & 2 & 2 & Medium & $\begin{array}{l}\text { Peringatan } \\
\text { pemakaian } \\
\text { APD lengkap } \\
\text { saat bertugas }\end{array}$ & Ahli K3 \\
\hline $\begin{array}{l}\text { Produksi } \\
\text { beton cetak }\end{array}$ & Terpeleset & $\begin{array}{l}\text { Cedera bahu } \\
\text { sebelah kiri }\end{array}$ & $\begin{array}{l}\text { Penggunaan } \\
\text { APD }\end{array}$ & 2 & 2 & Medium & $\begin{array}{l}\text { Memasang } \\
\text { peringatan } \\
\text { jalan licin }\end{array}$ & Ahli K3 \\
\hline $\begin{array}{l}\text { Memasang } \\
\text { pengamanan } \\
\text { асси mobil }\end{array}$ & $\begin{array}{l}\text { Aki mobil } \\
\text { meledak }\end{array}$ & $\begin{array}{l}\text { Muka dan } \\
\text { mata kena air } \\
\text { aki }\end{array}$ & $\begin{array}{l}\text { Penggunaan } \\
\text { APD }\end{array}$ & 2 & 3 & Medium & $\begin{array}{l}\text { Peringatan } \\
\text { pemakaian } \\
\text { APD lengkap } \\
\text { saat bertugas }\end{array}$ & Ahli K3 \\
\hline
\end{tabular}

Semua jenis APD yang disiapkan oleh PT. IGASAR wajib digunakan oleh para pekerja selama berada dalam lokasi kerja. Jika dilihat dari kenyataan di lapangan masih ada sejumlah pekerja yang tidak menggunakan APD dengan berbagai alasan, seperti tidak terbiasa menggunakannya, hanya memperlambat pekerjaan yang dilakukan. Terhadap pekerja yang tidak memakai APD selama berada dalam area kerja perusahaan akan diberikan peringatan.

Pengadaan Fasilitas Pemadam Kebakaran \& P3K

Pengadaan fasilitas kebakaran sangat diperlukan di area ataupun lokasi kerja. Hal ini didasarkan pada besarnya potensi bahaya berupa kebakaran dan ledakan dapat terjadi oleh tegangan listrik, korsleting 
listrik dan temperatur yang tinggi. Alat yang disediakan berupa alat pemadam kebakaran. Oleh karena itu PT IGASAR telah menyediakan alat pemadam kebakaran dan kotal P3K seperti pada Gambar 1.

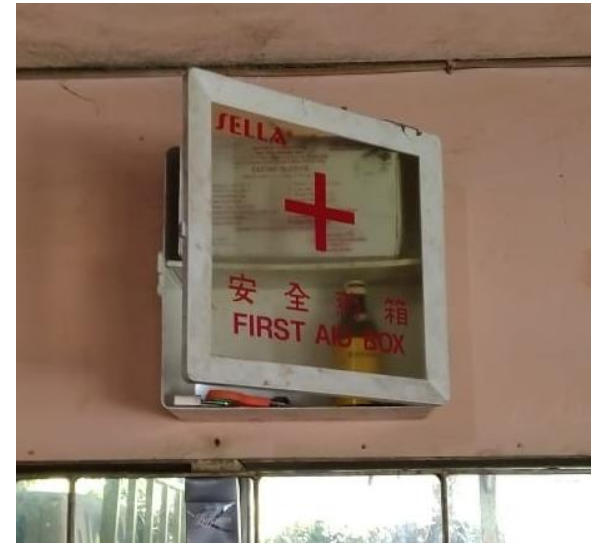

a

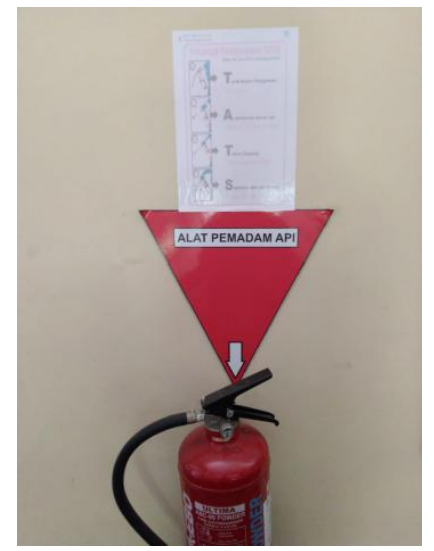

b

Gambar 1. a. Peletakan P3K, b. Alat pemadam kebakaran

PT. IGASAR telah menyediakan fasilitas P3K di area kerja, karena pentingnya pertolongan pertama bagi pekerja yang mengalami kecelakaan saat melakukan pekerjaan. Jika keadaan pekerja makin memburuk, maka akan dibawa ke rumah sakit.

\section{Penyediaan Rambu-rambu Keselamatan \& Monitoring SMK3}

PT. IGASAR dalam meminimalisir terjadinya kecelakaan kerja telah membuat rambu-rambu peringatan di setiap area yang dianggap rawan kecelakaan kerja. Selain itu, rambu-rambu keselamatan kerja ini juga memberitahu dan mengingatkan kepada pekerja untuk senantiasa hati-hati dalam bekerja. Adapun rambu-rambu kerjanya seperti awas lantai licin, mudah terbakar dan lain sebagainya. Ramburambu disesuaikan dengan letak dari kegiatan di tempat tersebut. Secara keseluruhan rambu-rambu keselamatan sudah ada di seluruh tempat yang berpotensi bahaya seperti Gambar 2.

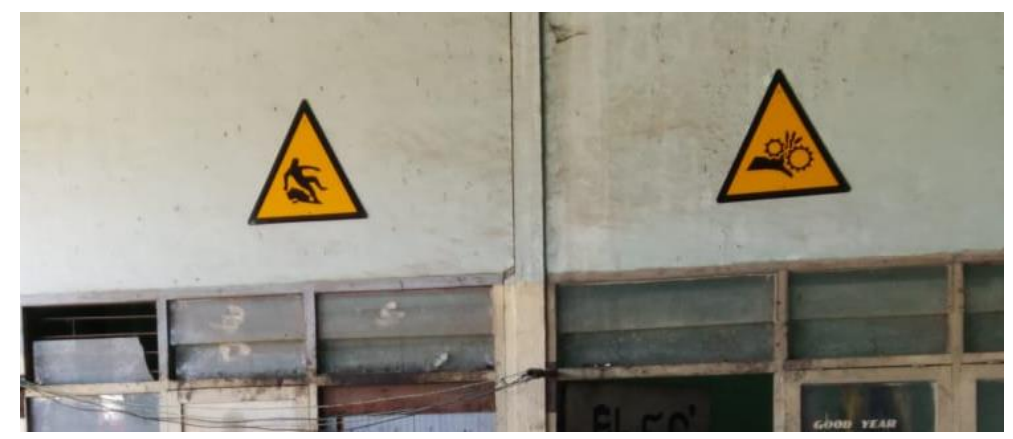

Gambar 2. Penempatan rambu keselamatan

Perusahaan telah melakukan peninjauan ulang terhadap SMK3 secara berkala, sehingga perusahaan dapat mengatasi implikasi K3 terhadap keseluruhan kegiatan, meminimalisir kecelakaan kerja serta dampak yang ditimbulkan terhadap kinerja perusahaan.

\section{Pemberian Jaminan Kesehatan}

Jika terjadi kecelakaan kerja pada karyawan, maka PT. IGASAR memberikan BPJS bagi setiap pekerjanya dan memberikan pelayanan kesehatan apabila terjadi kecelakaan saat bekerja yaitu berupa biaya perawatan rumah sakit dan tanggungan biaya duka cita saat terjadi kematian.

Berdasarkan tinjauan kinerja SMK3 yang telah dilakukan, pelaksanaan K3 PT. IGASAR telah terlaksana dengan baik berdasarkan kepada Peraturan Pemerintah Republik Indonesia No. 50 Tahun 2012, meskipun masih ditemukan adanya beberapa kriteria yang belum memenuhi. Kriteria-kriteria tersebut yaitu belum ditetapkannya petugas penanganan darurat (kategori minor), belum melakukan evaluasi terhadap kotak P3K (kategori mayor), dan belum memiliki petugas P3K yang berlisensi (kategori minor). Solusi dari permasalahan tersebut yaitu menetapkan petugas penanganan darurat, melakukan evaluasi terhadap kotak P3K yang isinya tidak lengkap dan menetapkan petugas P3K yang telah berlisensi. 
Hasil penerapan SMK3 mengacu pada Peraturan Pemerintah Republik Indonesia No. 50 Tahun 2012 di PT. IGASAR. Peraturan yang menjelaskan terdapat 12 Elemen dan 166 kriteria SMK3 yang menjadi acuan menurut peraturan tersebut. Evaluasi yang dilakukan dari 166 kriteria, PT. IGASAR telah memenuhi 157 kriteria $(94,57 \%)$ untuk tingkatan lanjutan penerapan SMK3 termasuk dalam tingkat penilaian penerapan memuaskan, dan kriteria yang belum terpenuhi sebanyak 9 kriteria. Dengan dilakukannya perbaikan secara terus menerus di bidang K3 ini sehingga pada tahun 2019 ini PT. IGASAR diberikan penghargaan zero accident karena nihil dan tidak ditemukannya kasus kecelakaan kerja pada Tahun 2019. Beberapa kegiatan pekerja di PT IGASAR dapat dilihat pada Gambar 3.
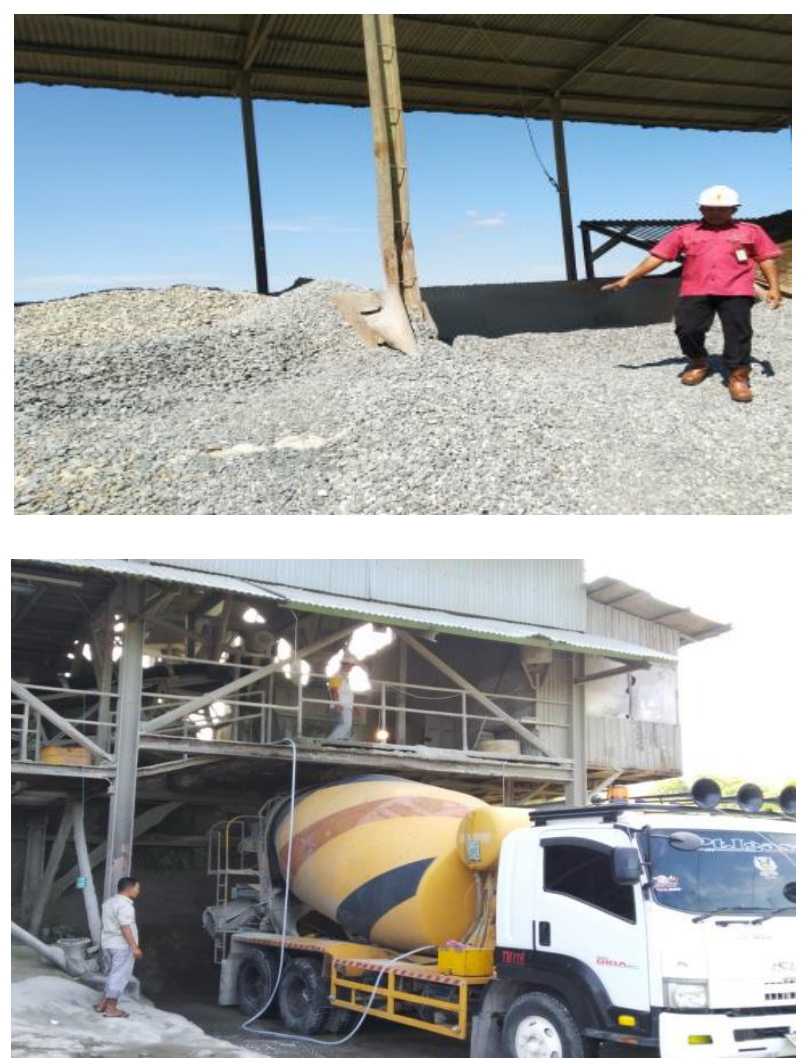

Gambar 3. Kegiatan di PT IGASAR

\section{Kesimpulan}

PT. IGASAR memiliki risk assessment untuk kegiatannya memiliki tingkat risiko sedang (medium risk) dengan 5 potensi bahaya yaitu jatuh dari kendaraan pada saat berangkat bekerja, tertimpa alat pada area produksi batching plan, terpeleset pada area produksi beton cetak, terjepit saat pengecekan kendaraan dan terluka akibat adanya aki yang meledak pada saat memasang pengamanan aki mobil. Pengendalian risiko dapat dilakukan dengan memberi alat pelindung diri; mengadakan dan menempatkan safety sign; melakukan maintenance peralatan; dan membuat batas area jalan..

\section{Referensi}

[1] Ramli, S, Sistem Managemen Keselamatan dan Kesehatan Kerja OHSAS 18001, PT Dian Rakyat, Jakarta, 2013.

[2] Suma'mur, Higiene Perusahaan dan Kesehatan Kerja, Sagung Seto, Jakarta, 2013.

[3] Evans, Jon. 2014. Safety first? R. Soc. Chem. J. http://www.rsc.org/chemistryworld/2014/05/safety-first, diakses 11/12/2019

[4] Sucipto, Keselamatan dan Kesehatan Kerja, Gosyen Publishing, Yogyakarta, 2014.

[5] Ihsan, T., \& Salami, I. R. S. "Hubungan Antara Bahaya Fisik Lingkungan Kerja Dan Beban Kerja Dengan Tingkat Kelelahan, "Dampak: Jurnal Teknik Lingkungan, UNAND, 10-16, 2015.

[6] Budiono, A. M. S, Jusuf, R. M, \& Pusparini, A, Bunga Rampai Hiperkes Dan KK, Higiene Perusahaan, Ergonomi, Kesehatan Kerja, Keselamatan Kerja (second edi), Badan Penerbit Universitas Diponegoro, Semarang, 2003. 
[7] Ihsan, T., Edwin, T., \& Irawan, R. O, "Analisis Risiko K3 Dengan Metode Hirarchy Pada Area Produksi PT Cahaya Murni Andalas Permai," Jurnal Kesehatan Masyarakat Andalas, 10(2), 179185. https://doi.org/10.24893/jkma.10.2.179-185. 2016.

[8] AS/NZS 4360. 2004. Risk management AS/NZS 4360: 2004, 44. https://doi.org/AS/NZS 4360

[9] Cooper, D. F, Tutorial Notes" the Australian and New Zealand Standard on Risk Management, As/Nzs 4360:2004. Broadleaf capital international, 2007.

[10] Tarwaka, Bakri, S. H. A, \& Sudiajeng, L, Ergonomi untuk Keselamatan, Kesehatan Kerja dan Produktivitas, 2004.

[11] Luo T, Wu C, "Safety information cognition: A new methodology of safety science in urgent need to be established," Journal of Cleaner Production, 209 (2019):1182-1194, 2018.

[12] Nitsche CI. Promoting safety culture: An overview of collaborative chemical safety information initiatives. J. Chem. Health Safety (2019), https://doi.org/10.1016/j.jchas.2018.12.004

[13] Leiter AM, Rheinberger CM, "Risky sports and the value of safety information," Journal of Economic Behavior \& Organization, 131 (2016):328-345, 2016.

[14] Scheveneels S, Boddeza Y, Ceulaer TD, Hermans D, "Ruining the surprise: The effect of safety information before extinction on return of fear," Journal of Behavior Therapy and Experimental Psychiatry, 63 (2019):73-78, 2018

[15] Drupsteen L, Boustras G, "Exploring effectiveness of safety information for workplace visitors. Safety Science," 88:224-231, 2016.

[16] Sarshar S. Haugen S, Skjerve AB, "Risk-related information needed through the planning process for offshore activities," Journal of Loss Prevention in the Process Industries, 56:10-17, 2018. 